\title{
Development of a prognostic model of glioma based on immune-related genes
}

\author{
JING-JING WANG $^{1 *}$, HAN WANG $^{2 *}$, BAO-LONG ZHU $^{1 *}$, XIANG WANG ${ }^{1}$, YONG-HONG QIAN ${ }^{3}$, LEI XIE $^{1}$, \\ WEN-JIE WANG ${ }^{4}$, JIE ZHU ${ }^{5}$, XING-YU CHEN ${ }^{6}$, JING-MEI WANG ${ }^{7}$ and ZHI-LIANG DING ${ }^{8}$ \\ ${ }^{1}$ Department of Oncology, Taizhou Hospital of Traditional Chinese Medicine, Taizhou, Jiangsu 225300; \\ ${ }^{2}$ Department of Oncology, Jining Cancer Hospital, Jining, Shandong 272000; ${ }^{3}$ Department of Radio-Oncology, \\ Taizhou Hospital of Traditional Chinese Medicine, Taizhou, Jiangsu 225300; ${ }^{4}$ Department of Radio-Oncology, \\ The Affiliated Suzhou Hospital of Nanjing Medical University, Suzhou, Jiangsu 215001; ${ }^{5}$ Department of Oncology, \\ Changzhou Traditional Chinese Medical Hospital, Changzhou, Jiangsu, 213003; ${ }^{6}$ Department of General Surgery, \\ Taizhou Fourth People's Hospital, Taizhou, Jiangsu 225300; ${ }^{7}$ Department of Geriatrics, \\ The First Affiliated Hospital of Zhejiang University, Hangzhou, Zhejiang $310002 ;{ }^{8}$ Department of Neurosurgery, \\ The Affiliated Suzhou Hospital of Nanjing Medical University, Suzhou, Jiangsu 215001, P.R. China
}

Received February 13, 2020; Accepted October 9, 2020

DOI: $10.3892 / 01.2020 .12377$

\begin{abstract}
Glioma is the most common type of primary brain cancer, and the prognosis of most patients with glioma, and particularly that of patients with glioblastoma, is poor. Tumor immunity serves an important role in the development of glioma. However, immunotherapy for glioma has not been completely successful, and thus, comprehensive examination of the immune-related genes (IRGs) of glioma is required. In the present study, differentially expressed genes (DEGs) and differentially expressed IRGs (DEIRGs) were identified using the edgeR package. Kyoto Encyclopedia of Genes and Genomes (KEGG) pathway analysis was used for functional enrichment analysis of DEIRGs. Survival-associated IRGs were selected via univariate Cox regression analysis. A The Cancer Genome Atlas prognostic model and GSE43378 validation model were established using lasso-penalized Cox regression analysis. Based on the median risk score value, patients were divided into high-risk and low-risk groups for clinical analysis. Receiver operating characteristic curve and nomogram analyses were used to assess the accuracy of the models. Reverse transcription-quantitative PCR was performed to measure the expression levels of relevant genes, such as cyclin-dependent kinase 4 (CDK4), interleukin 24 (IL24), NADPH oxidase 4 (NOX4), bone morphogenetic protein 2 (BMP2) and baculoviral IAP
\end{abstract}

Correspondence to: Dr Zhi-Liang Ding, Department of Neurosurgery, The Affiliated Suzhou Hospital of Nanjing Medical University, 26 Daoqian, Suzhou, Jiangsu 215001, P.R. China

E-mail: cxy442941186@163.com

${ }^{*}$ Contributed equally

Key words: glioma, The Cancer Genome Atlas, GSE43378, immune-related gene, prognostic model, immune cells repeat containing 5 (BIRC5). A total of 3,238 DEGs, including 1,950 upregulated and 1,288 downregulated DEGs, and 97 DEIRGs, including 60 upregulated and 37 downregulated DEIRGs, were identified. 'Neuroactive ligand-receptor interaction' and 'Cytokine-cytokine receptor interaction' were the most significantly enriched pathways according to KEGG pathway analysis. A prognostic model and a validation prognostic model were created for glioma, including 15 survival-associated IRGs (FCER1G, NOX4, TRIM5, SOCS1, APOBEC3C, BIRC5, VIM, TNC, BMP2, CMTM3, IL24, JAG1, CALCRL, HNF4G and CDK4). Furthermore, multivariate Cox regression analysis results suggested that age, high WHO Grade by histopathology, wild type isocitrate dehydrogenase 1 and high risk score were independently associated with poor overall survival. The infiltration of $\mathrm{B}$ cells, $\mathrm{CD} 8^{+} \mathrm{T}$ cells, dendritic cells, macrophages and neutrophils was positively associated with the prognostic risk score. In the present study, several clinically significant survival-associated IRGs were identified, and a prognosis evaluation model of glioma was established.

\section{Introduction}

Glioma is the most common type of primary brain cancer, and originates from neuroepithelial cells $(1,2)$. According to the World Health Organization (WHO) standard, the histopathological types of glioma vary from benign ependymoma to the most aggressive glioblastoma $(\mathrm{GBM})(3,4)$. In recent years, molecular changes and mutations in isocitrate dehydrogenase $1 / 2$ (IDH1/2) have become increasingly important in the diagnosis and prognosis evaluation of glioma (5). Surgical resection is the main treatment of intracranial tumors; however, certain patients cannot undergo surgery (6). Furthermore, the effect of chemotherapy is limited due to the existence of the blood-brain barrier (7). Therefore, despite the progress of conventional treatment, such as surgery, radiotherapy and chemotherapy, the prognosis of most patients with glioma, and particularly that of patients with GBM, remains poor $(4,8)$. 
Tumor immunity serves an important role in the occurrence, development and invasion of tumors (9). Immunotherapy has been considered as a potential effective cancer therapy. Tumor-promoting immune disorder is considered to be one of the enabling features of glioma (10). Meanwhile, some studies have demonstrated that immune status is closely related to the prognosis of glioma (11). The immune microenvironment is composed of glioma associated immune cells, such as microglia, macrophages and $\mathrm{B}$ cells and immunoregulatory factors, such as IL-6, IL-10 and TGF $\beta$ which regulate the progression of glioma (12). However, immunotherapy for glioma has not achieved great success (12). Therefore, it is important to understand the molecular mechanism of glioma in order to evaluate the prognosis and to identify effective treatments for patients with glioma. The present study established an immune-related gene prognostic model (IRGPM) by profiling an immune-related gene (IRG) dataset in The Cancer Genome Atlas (TCGA) database. Subsequently, a validation model was constructed to evaluate the feasibility of the prognostic model and based on the prognosis model, the immune status and clinical prognosis of patients with glioma were further studied. The present study assessed the prognostic significance and clinical application value of IRGs in glioma, providing evidence for the prognosis evaluation and personalized treatment of patients with glioma.

\section{Materials and methods}

Subjects. A total of 20 pairs of glioma specimens and the corresponding adjacent normal specimens were obtained from patients with glioma (12 men and 8 women; median age, 49 years; age range, 15-75 years), undergoing surgery at the Affiliated Suzhou Hospital of Nanjing Medical University (Suzhou, China) from September 2015 to February 2019. In the non-functional area, the 'adjacent' tissues were $1 \mathrm{~cm}$ away from the glioma tissues. In the functional area, the tumor was usually resected along the edge. The inclusion criteria were as follows: i) Histopathology was confirmed as glioma; and ii) the age range of the patients was $15-75$ years. Prior to surgery, written informed consent was collected from the patients/legal guardians. The present study was approved by the Medical Ethics Committees of the Affiliated Suzhou Hospital of Nanjing Medical University (Suzhou, China).

Data collection and processing. Clinical information and transcriptome RNA-sequencing data of patients with glioma were obtained from TCGA data portal (https://portal.gdc. cancer.gov/) and the Gene Expression Omnibus (GEO) database (https://www.ncbi.nlm.nih.gov/geo/; GSE43378). TCGA (13) contains data for 1,066 glioma tissues and 112 adjacent normal tissues; and GSE43378 (14) includes data for 117 glioma tissues. The IRGs list was downloaded from the Immunology Database and Analysis Portal (https://www. immport.org/resources) (15).

Identification of differentially expressed genes (DEGs) and differentially expressed IRGs (DEIRGs). Using the edgeR package (v3.52; http://bioconductor.org/packages/edgeR/), the present study identified the DEGs for glioma in the TCGA database [ $[\log 2$ fold change (FC)|>1.0 and false discovery rate $(\mathrm{FDR})$ adjusted to $\mathrm{P}<0.05](16)$. Using the gplots and heatmap in the $\mathrm{R}$ platform, volcano plots and heat maps of DEGs were generated. By intersecting the acquired DEGs list with the IRG list, DEIRGs were obtained. By comparison with the GSE43378 dataset, the DEIRGs expressed in both the TCGA dataset and GSE43378 were obtained.

Functional enrichment analysis. In order to improve the understanding of the underlying biological mechanism of these IRGs, Kyoto Encyclopedia of Genes and Genomes (KEGG) (https://www.kegg.jp/) pathway analysis was performed using the DAVID v.6.8 (https://david.ncifcrf.gov/) online tool (16). Additionally, a visualized network was constructed using Cytoscape v.3.6.1 (https://cytoscape.org/). KEGG pathway analyses were based on the threshold of FDR $<0.05$.

Development of the IRGPM and validation model. A prognostic model was developed using univariate Cox regression analysis and lasso-penalized Cox regression analysis. Additionally, relevant prognostic variables were adjusted, including age, sex, WHO grade and IDH1-wild type (WT). Survival-associated IRGs were obtained via univariate Cox regression analysis using the survival package 3.2-3 in the $\mathrm{R}$ platform 3.2.5 (https://www.r-project.org/). In order to observe the relationship between risk score and prognosis, dichotomy was used. Based on the median risk score value (0.2068), patients with glioma were classified into high-risk score and low-risk score groups. In order to evaluate the feasibility of the prognostic model, a validation prognostic model was constructed in the GSE43378 dataset. Furthermore, patients in the GSE43378 dataset were divided into two groups based on the median risk score. The survival of the two groups of patients was analyzed by Kaplan-Meier (KM) analysis using GraphPad Prism v. 8.3.0 (SPSS Inc.). The risk score calculation formula was as follows:

$$
\text { Survival risk score }=\sum_{i=1}^{k}\left(C_{i} \times V_{i}\right)
$$

In the formula, $k$ represents the number of mRNA, $C_{i}$ represents the coefficient of mRNA in multivariate Cox regression analysis and $V_{i}$ represents the expression levels of mRNA.

The formula used was as follows: [FCER1G expression $\mathrm{x}$ $(0.00350)]+[$ NOX4 expression $x(0.03959)]+[$ TRIM5 expression $\mathrm{x}(0.04868)]+[\mathrm{SOCS} 1$ expression $\mathrm{x}(0.02350)]+[$ APOBEC $3 \mathrm{C}$ expression $\mathrm{x}(0.02236)]+[\mathrm{BIRC} 5$ expression $\mathrm{x}(0.01586)]+[\mathrm{VIM}$ expression $\mathrm{x}(0.00005)]+[\mathrm{TNC}$ expression $\mathrm{x}(0.00073)]+[\mathrm{BMP} 2$ expression $\mathrm{x}(-0.01722)]+[$ CMTM3 expression $\mathrm{x}(0.00992)]+$ [IL24 expression $x(0.12305)]+[\mathrm{JAG} 1$ expression $\mathrm{x}(0.00609)]$ $+[$ CALCRL expression $x(-0.01003)]+[$ HNF4G expression $x$ $(0.05241)]+[\mathrm{CDK} 4$ expression $\mathrm{x}(0.00008)]$.

Construction of prognosis-related nomogram and receiver operating characteristic (ROC) curves. Considering that the risk score is a continuous variable, the linear predictor was used in the verification of the nomogram and ROC curve to further verify the accuracy of the prognostic model. The nomogram and ROC curve were established using the 
Table I. Primer sequences used for reverse transcription-quantitative PCR.

\begin{tabular}{ll}
\hline Primer & \multicolumn{1}{c}{ Sequence, 5'-3' } \\
\hline CDK4 forward & CATGTAGACCAGGACCTAAGG \\
CDK4 reverse & AACTGGCGCATCAGATCCTAG \\
IL24 forward & ATGAATTTTCAACAGAGAGGGCTG \\
IL24 reverse & GCAGAAATTCTACAAGCTCTGA \\
NOX4 forward & TCGCCAACGAAGGGGTTAAA \\
NOX4 reverse & GCAACGTCAGCAGCATGTAG \\
BMP2 forward & CGCAGCTTCCACCATGAAGAA \\
BMP2 reverse & GAATCTCCGGGTTGTTTTCCCACT \\
BIRC5 forward & CGCATCTCTACATTCAAG \\
BIRC5 reverse & ATGTTCCTCTCTCGTGAT \\
GAPDH forward & CAACGAATTTGGCTACAGCA \\
GAPDH reverse & AGGGGTCTACATGGCAACTG
\end{tabular}

BIRC5, baculoviral IAP repeat containing 5; BMP2, bone morphogenetic protein 2; NOX4, NADPH oxidase 4 .

edgeR package (17). The concordance index (C-index) was used to evaluate the accuracy of the nomogram by bootstrap method with 1,000 resamplings.

Association between the IRGPM and immune cell infiltration . The abundances of tumor-infiltrating immune cells were analyzed and visualized using the Tumor Immune Estimation Resource online database (TIMER 2.0; https://cistrome. shinyapps.io/timer/) (18). The abundance of six subtypes of tumor-infiltrating immune cells $\left(\mathrm{CD} 4^{+} \mathrm{T}\right.$ cells, $\mathrm{CD} 8^{+} \mathrm{T}$ cells, B cells, macrophages, dendritic cells and neutrophils) was evaluated. Subsequently, the association between the IRGPM and immune cell infiltration was analyzed using TIMER by downloading immune infiltrate levels of patients with glioma from the Immunology Database and Analysis Portal.

Reverse transcription-quantitative PCR (RT-qPCR). To evaluate the expression levels of key genes in the prognosis model, five genes [cyclin-dependent kinase 4 (CDK4), interleukin-24 (IL-24), NADPH oxidase 4 (NOX4), bone morphogenetic protein 2 (BMP2) and baculoviral IAP repeat containing 5 (BIRC5)] were randomly selected for RT-qPCR verification. TRIzol ${ }^{\circledR}$ reagent (Invitrogen; Thermo Fisher Scientific, Inc.) was used to extract total RNA from 20 glioma specimen and 20 normal specimens, and then the First Strand cDNA synthesis kit (New England BioLabs, Inc.) was used for reverse transcription. A SYBR Green PCR kit (Applied Biological Materials Inc.) was used for amplification. The RNA expression was standardized against GAPDH according to the $2^{-\Delta \Delta C q}$ method (19). Unpaired t-test was used to evaluate the difference in gene expression between tumor specimen and normal specimen. The PCR primers used are shown in Table I. The temperature protocol of reverse transcription was as follows: Pre denaturation at $37^{\circ} \mathrm{C}$ for $15 \mathrm{~min}$; denaturation at $85^{\circ} \mathrm{C}$ for $5 \mathrm{sec}$ and annealing at $10^{\circ} \mathrm{C}$. The thermocycling conditions for $\mathrm{qPCR}$ were as follows: Initial denaturation at $95^{\circ} \mathrm{C}$ for $10 \mathrm{~min} ; 40$ cycles at $95^{\circ} \mathrm{C}$ for $30 \mathrm{sec}, 60^{\circ} \mathrm{C}$ for $30 \mathrm{sec}$ and $72^{\circ} \mathrm{C}$ for $30 \mathrm{sec}$; extension at $75^{\circ} \mathrm{C}$ for $7 \mathrm{~min}$. The experiment was repeated three times.

Statistical analysis. Survival analysis of patients with glioma was performed using the 'survival' package in $\mathrm{R}$. The Kaplan-Meier method was used to construct survival curves, and the log-rank test was used to compare differences between two groups. The area under the curve of the survival ROC curve was calculated using the survival ROC R software package 1.12 (https://cran.r-project.org/web/packages/survivalROC/). Unpaired t-test was used to evaluate the difference in gene expression between tumor specimen and normal specimen. $\mathrm{P}<0.05$ was considered to indicate a statistically significant difference.

\section{Results}

Identification of DEGs and DEIRGs for glioma in TCGA. Significant DEGs were identified in glioma using the 'edgeR' package in $\mathrm{R}$ software. A total of 3,238 DEGs, including 1,950 upregulated and 1,288 downregulated DEGs, were identified (Fig. 1A and C). Among these DEGs, 97 DEIRGs, including 60 upregulated and 37 downregulated DEIRGs, were identified as DEGS and included in the immune gene list in TCGA (Fig. 1B and D). In addition, co-expressed IRGs were identified using the intersection of TCGA database and GSE43378 (data not shown).

Gene functional enrichment analysis of DEIRGs. Following enrichment analysis, the top $10 \mathrm{KEGG}$ pathways were presented in a scatter plot (Fig. 2A). According to the associations among the top five KEGG pathways and the involved IRGs, a visual network was constructed using Cytoscape v3.6.1 (Fig. 2B). The top five significant KEGG pathways were as follows: 'Neuroactive ligand-receptor interaction' (hsa04080), 'Cytokine-cytokine receptor interaction' (hsa04060), 'Viral protein interaction with cytokine and cytokine receptor' (hsa04061), 'Intestinal immune network for IgA production' (hsa04672) and 'cAMP signaling pathway' (hsa04024).

Construction of the IRGPM and validation model. A total of 72 survival-associated IRGs were identified using univariate Cox regression analysis (Fig. 3), and these were significantly associated with overall survival (OS) in glioma. Lasso-penalized Cox regression analysis was performed to identify the genes in the prognostic model (Fig. 4C), and the IRGPM for TCGA was constructed (Fig. 4). Furthermore, using GSE43378, a validation model that classified patients into high- and low-risk score groups was established based on the median risk score (Fig. S1).

Clinical outcome and prognostic model in patients with glioma. Patients were classified into two groups (high-risk and low-risk) based on the median risk score as the cut-off, and KM analysis was performed to analyze patient prognosis. In the prognostic model, the high-risk group had worse OS compared with the low-risk group of patients with glioma $(\mathrm{P}<0.01$; Fig. 5A) and patients with GBM ( $\mathrm{P}<0.05$; Fig. 5B). In the validation model, the high-risk score group also had worse OS compared with the low-risk score group of patients with 
A

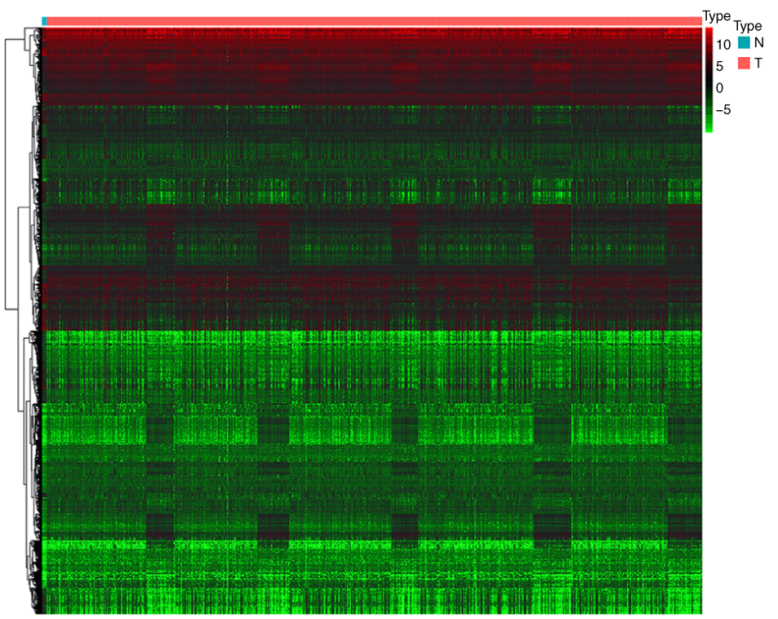

C

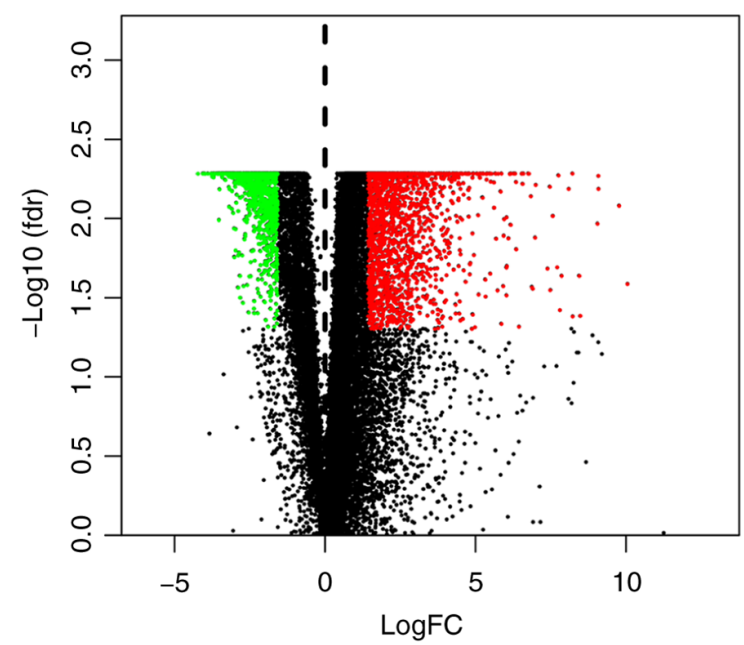

B

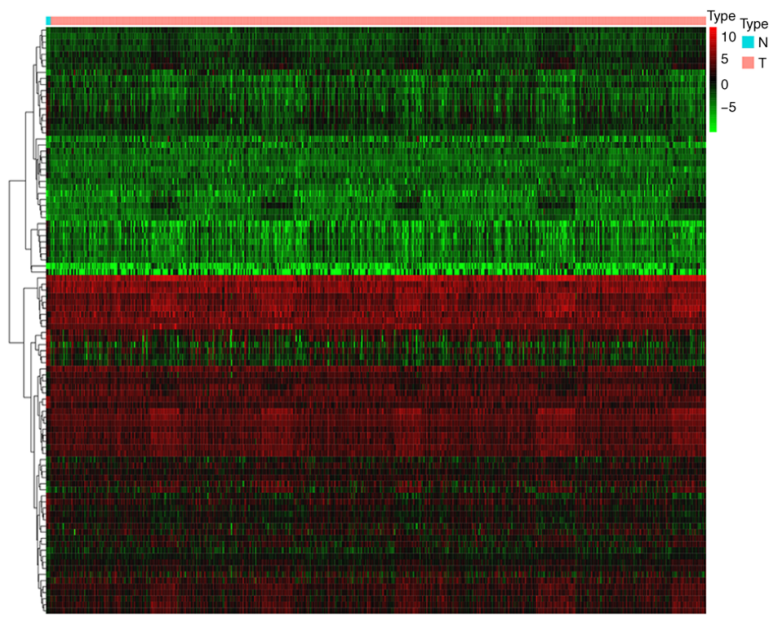

$\mathrm{D}$

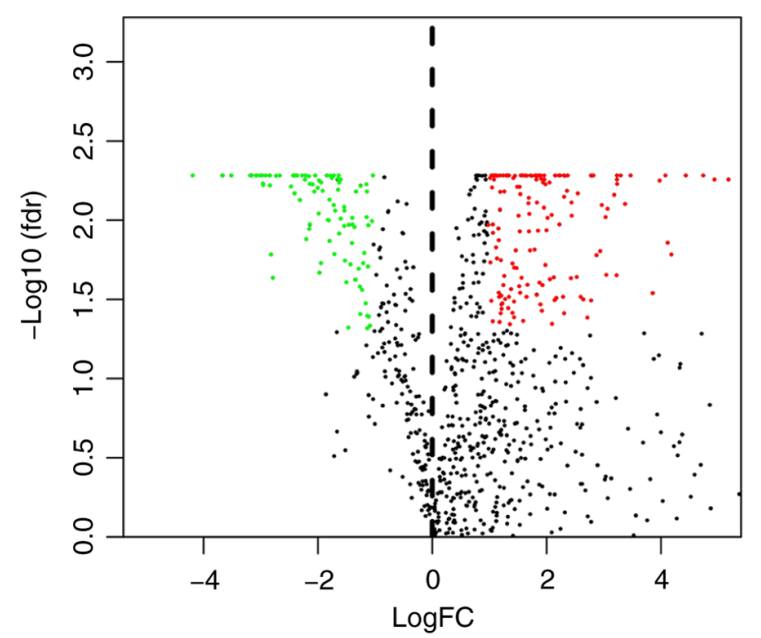

Figure 1. DEGs and DEIRGs in The Cancer Genome Atlas. Heatmap of (A) DEGs and (B) DEIRGs between glioma and normal tissues. Volcano plot of (C) DEGs and (D) DEIRGs between glioma and normal tissues. Red dots represent upregulated genes and green dots represent downregulated genes with statistical significance. DEGs, differentially expressed genes; DEIRGs, differentially expressed immune-related genes; FC, fold change; fdr, false discovery rate; $\mathrm{N}$, normal; $\mathrm{T}$, tumor.

glioma $(\mathrm{P}<0.01$; Fig. S2A) and patients with GBM $(\mathrm{P}<0.01$; Fig. S2B).

In TCGA group of the prognostic model, univariate analysis (Fig. 5C) demonstrated that high age [hazard ratio $(\mathrm{HR})=1.073$; 95\% CI, 1.016-1.084; $\mathrm{P}<0.001]$, high WHO grade $(\mathrm{HR}=4.702$; 95\% CI, 3.779-5.850; P<0.001), IDH1-WT $(\mathrm{HR}=1.482$; 95\% CI, 1.030-2.130; $\mathrm{P}=0.034)$ and high risk score $(\mathrm{HR}=3.979$; 95\% CI, 3.380-4.685; $\mathrm{P}<0.001)$ were significant prognostic factors for poor prognosis. In the multivariate Cox regression analysis (Fig. 5D), age (HR=1.046; 95\% CI, 1.033-1.059; $\mathrm{P}<0.001)$, high WHO grade $(\mathrm{HR}=1.705 ; 95 \% \mathrm{CI}, 1.257-2.314$; $\mathrm{P}<0.001)$, IDH1-WT $(\mathrm{HR}=2.946 ; 95 \% \mathrm{CI}, 2.000-4.339$; $\mathrm{P}<0.001)$ and high risk score $(\mathrm{HR}=2.461 ; 95 \% \mathrm{CI}, 1.945-3.113$; $\mathrm{P}<0.001)$ were identified to be independently associated with poor OS.

In the GSE43378 validation prognostic model, univariate analysis (Fig. S2C) indicated that high age (HR=1.032; 95\% CI, 1.011-1.054; $\mathrm{P}=0.003)$, high $\mathrm{WHO}$ grade $(\mathrm{HR}=2.357$; 95\% CI, 1.400-3.969; $\mathrm{P}=0.001)$ and high risk score $(\mathrm{HR}=13.708 ; 95 \% \mathrm{CI}, 4.579-41.037$; $\mathrm{P}<0.001)$ were significant prognostic factors for poor prognosis. Furthermore, in the multivariate Cox regression analysis (Fig. S2D), age ( $\mathrm{HR}=1.025 ; 95 \% \mathrm{CI}, 1.002-1.048 ; \mathrm{P}=0.033)$, high $\mathrm{WHO}$ grade $(\mathrm{HR}=1.911 ; 95 \% \mathrm{CI}, 1.068-3.419 ; \mathrm{P}=0.029)$ and high risk score ( $\mathrm{HR}=6.940 ; 95 \% \mathrm{CI}, 2.024-23.802 ; \mathrm{P}=0.002)$ were identified to be independently associated with poor OS.

Assessing the accuracy of the prognostic model. A nomogram and ROC curve were generated to examine the accuracy of the prognostic model. The ROC curve analysis of TCGA prognostic model is presented in Fig. 6A, and the risk score area under the curve was 0.886 , suggesting that the TCGA IRGPM could be used to assess survival. Furthermore, TCGA prognostic model nomogram is illustrated in Fig. 6B, and the C-index was identified to be 0.741 (data not shown).

The ROC curve analysis of the validation prognostic model is presented in Fig. S3A, with an area under the curve of 0.688 . In addition, the GSE43378 validation model nomogram is shown in Fig. S3B.

Prognostic model and immune cell infiltration correlation analysis. The correlation between the risk score and 
A

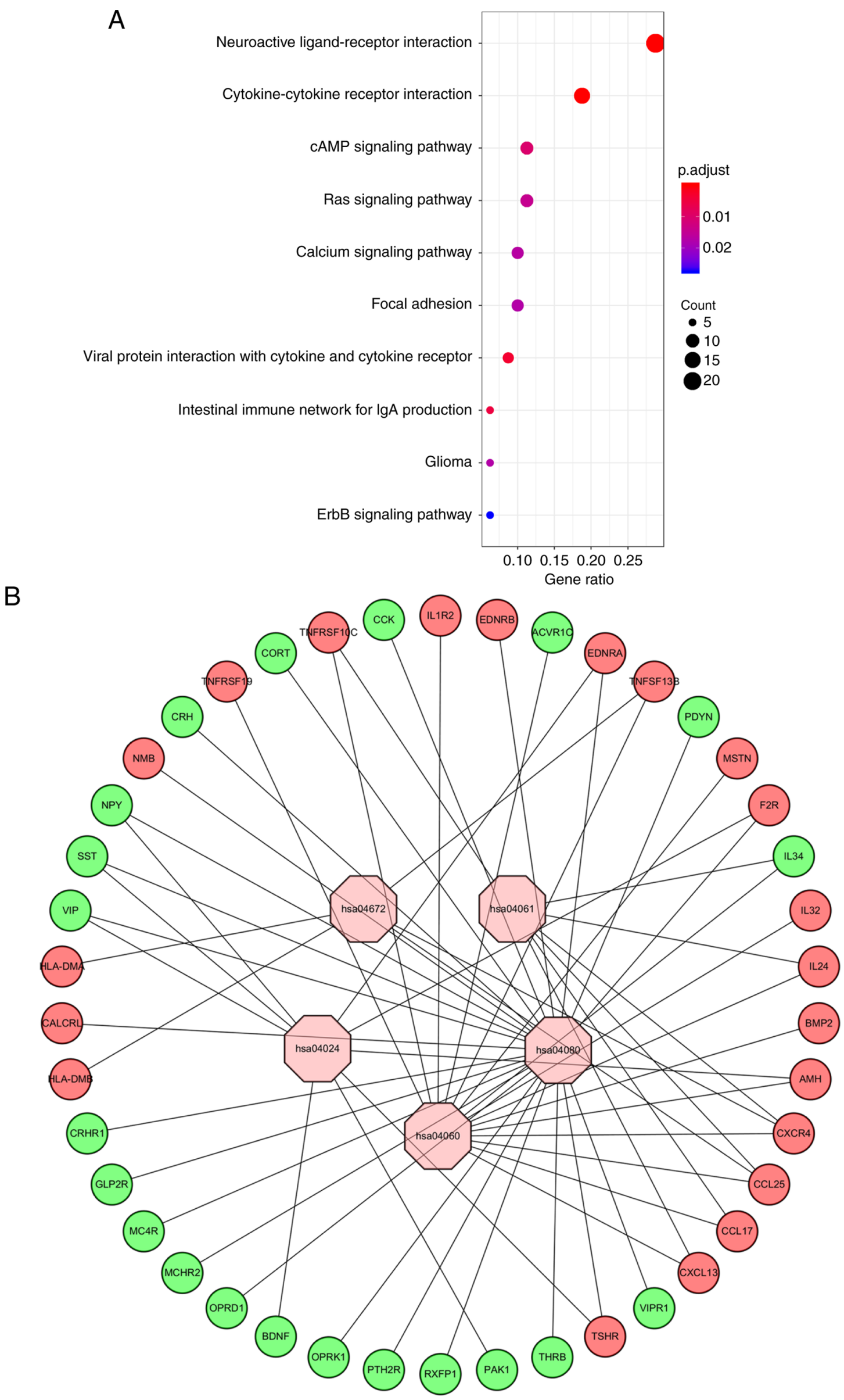

Figure 2. Enriched KEGG pathways and the intersection network. (A) Top 10 KEGG enrichment pathways of differentially expressed IRGs. (B) Visual intersection network of the top five KEGG pathways and the involved IRGs. IRGs, immune-related genes; KEGG, Kyoto Encyclopedia of Genes and Genomes. 


\begin{tabular}{|c|c|c|}
\hline & $\mathrm{P}$-value & Hazard ratio $(95 \% \mathrm{Cl})$ \\
\hline CD1D & $<0.001$ & $1.265(1.186-1.349)$ \\
\hline FCER1G & $<0.001$ & $1.012(1.010-1.013)$ \\
\hline HLA-DMA & $<0.001$ & $1.024(1.019-1.029)$ \\
\hline HLA-DMB & $<0.001$ & $1.038(1.031-1.045)$ \\
\hline PSMB8 & $<0.001$ & $1.019(1.015-1.022)$ \\
\hline PDIA2 & $<0.001$ & $0.867(0.821-0.915)$ \\
\hline CAMP & 0.001 & $1.070(1.027-1.114)$ \\
\hline CXCL13 & $<0.001$ & $1.017(1.010-1.023)$ \\
\hline S100A10 & $<0.001$ & $1.006(1.005-1.008)$ \\
\hline S100A2 & $<0.001$ & $1.179(1.124-1.237)$ \\
\hline NOD2 & $<0.001$ & $1.417(1.224-1.639)$ \\
\hline SLC40A1 & $<0.001$ & $1.034(1.024-1.043)$ \\
\hline NOX4 & $<0.001$ & $2.209(1.954-2.498)$ \\
\hline TRIM5 & $<0.001$ & $1.268(1.219-1.319)$ \\
\hline SOCS1 & $<0.001$ & $1.171(1.142-1.202)$ \\
\hline F2R & $<0.001$ & $1.023(1.015-1.030)$ \\
\hline ELN & $<0.001$ & $1.016(1.012-1.019)$ \\
\hline WNT5A & $<0.001$ & $1.090(1.054-1.127)$ \\
\hline АРОВЕСЗС & $<0.001$ & $1.082(1.071-1.094)$ \\
\hline MASP1 & $<0.001$ & $0.945(0.924-0.967)$ \\
\hline BIRC5 & $<0.001$ & $1.039(1.031-1.047)$ \\
\hline VIM & $<0.001$ & $1.002(1.002-1.002)$ \\
\hline VCAM1 & $<0.001$ & $1.018(1.010-1.027)$ \\
\hline GBP2 & 0.039 & $1.006(1.000-1.011)$ \\
\hline CCL25 & 0.020 & $1.283(1.041-1.581)$ \\
\hline CXCR4 & $<0.001$ & $1.016(1.013-1.020)$ \\
\hline FAM19A4 & 0.003 & $0.599(0.428-0.838)$ \\
\hline FAM19A1 & $<0.001$ & $0.801(0.725-0.887)$ \\
\hline FAM19A2 & $<0.001$ & $0.609(0.522-0.710)$ \\
\hline PRKCB & $<0.001$ & $0.944(0.920-0.968)$ \\
\hline SEMA4A & $<0.001$ & $0.761(0.690-0.838)$ \\
\hline TNC & $<0.001$ & $1.008(1.006-1.010)$ \\
\hline EDNRB & $<0.001$ & $0.993(0.990-0.996)$ \\
\hline BMP2 & $<0.001$ & $0.920(0.904-0.936)$ \\
\hline CCK & 0.009 & $0.986(0.976-0.997)$ \\
\hline СМТМ3 & $<0.001$ & $1.065(1.055-1.075)$ \\
\hline CORT & 0.003 & $0.793(0.682-0.922)$ \\
\hline GREM2 & 0.005 & $0.804(0.690-0.936)$ \\
\hline IL24 & $<0.001$ & $3.519(2.775-4.463)$ \\
\hline IL32 & $<0.001$ & $1.054(1.038-1.069)$ \\
\hline JAG1 & $<0.001$ & $1.054(1.043-1.065)$ \\
\hline MDK & $<0.001$ & $1.012(1.010-1.014)$ \\
\hline MIA & 0.009 & $1.107(1.026-1.195)$ \\
\hline NMB & $<0.001$ & $0.997(0.996-0.999)$ \\
\hline NPY & 0.039 & $0.987(0.975-0.999)$ \\
\hline PGF & 0.004 & $0.958(0.931-0.987)$ \\
\hline SST & 0.002 & $0.983(0.972-0.994)$ \\
\hline TNFSF13B & 0.037 & $1.011(1.001-1.021)$ \\
\hline VIP & 0.003 & $0.876(0.803-0.955)$ \\
\hline ACVR1C & $<0.001$ & $0.486(0.357-0.662)$ \\
\hline ANGPTL2 & $<0.001$ & $0.979(0.974-0.984)$ \\
\hline AR & 0.002 & $1.129(1.047-1.218)$ \\
\hline CALCRL & $<0.001$ & $0.943(0.931-0.956)$ \\
\hline CRHR1 & $<0.001$ & $0.538(0.441-0.656)$ \\
\hline EGFR & $<0.001$ & $1.002(1.001-1.003)$ \\
\hline GLP2R & 0.009 & $0.571(0.375-0.868)$ \\
\hline HNF4G & $<0.001$ & $1.922(1.674-2.206)$ \\
\hline IL17RD & $<0.001$ & $0.906(0.869-0.945)$ \\
\hline IL1R2 & $<0.001$ & $1.147(1.105-1.191)$ \\
\hline MCHR2 & 0.004 & $0.711(0.565-0.895)$ \\
\hline NR5A2 & $<0.001$ & $1.778(1.291-2.447)$ \\
\hline OPRK1 & 0.017 & $0.648(0.454-0.925)$ \\
\hline PTH2R & 0.013 & $0.650(0.463-0.914)$ \\
\hline RXFP1 & $<0.001$ & $0.536(0.399-0.719)$ \\
\hline THRB & $<0.001$ & $0.856(0.794-0.923)$ \\
\hline TNFRSF10C & $<0.001$ & $1.418(1.318-1.525)$ \\
\hline TNFRSF19 & $<0.001$ & $1.083(1.067-1.100)$ \\
\hline VIPR1 & 0.002 & $0.718(0.585-0.882)$ \\
\hline CD244 & $<0.001$ & $4.098(2.828-5.938)$ \\
\hline PRKCG & $<0.001$ & $0.953(0.929-0.979)$ \\
\hline PAK3 & $<0.001$ & $0.787(0.734-0.844)$ \\
\hline CDK4 & $<0.001$ & $1.001(1.001-1.001)$ \\
\hline
\end{tabular}

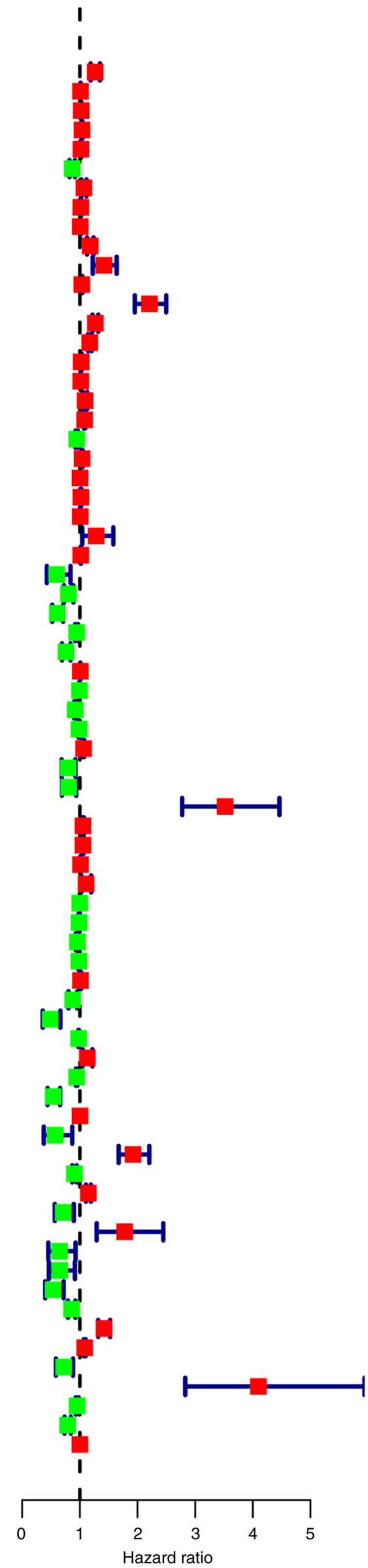

Figure 3. Expression profiles of survival-associated IRGs. Forest plot of hazard ratios showing the survival-associated IRGs in glioma. The red dots represent upregulated genes and green dots represent downregulated genes. IRGs, immune-related genes. 
A
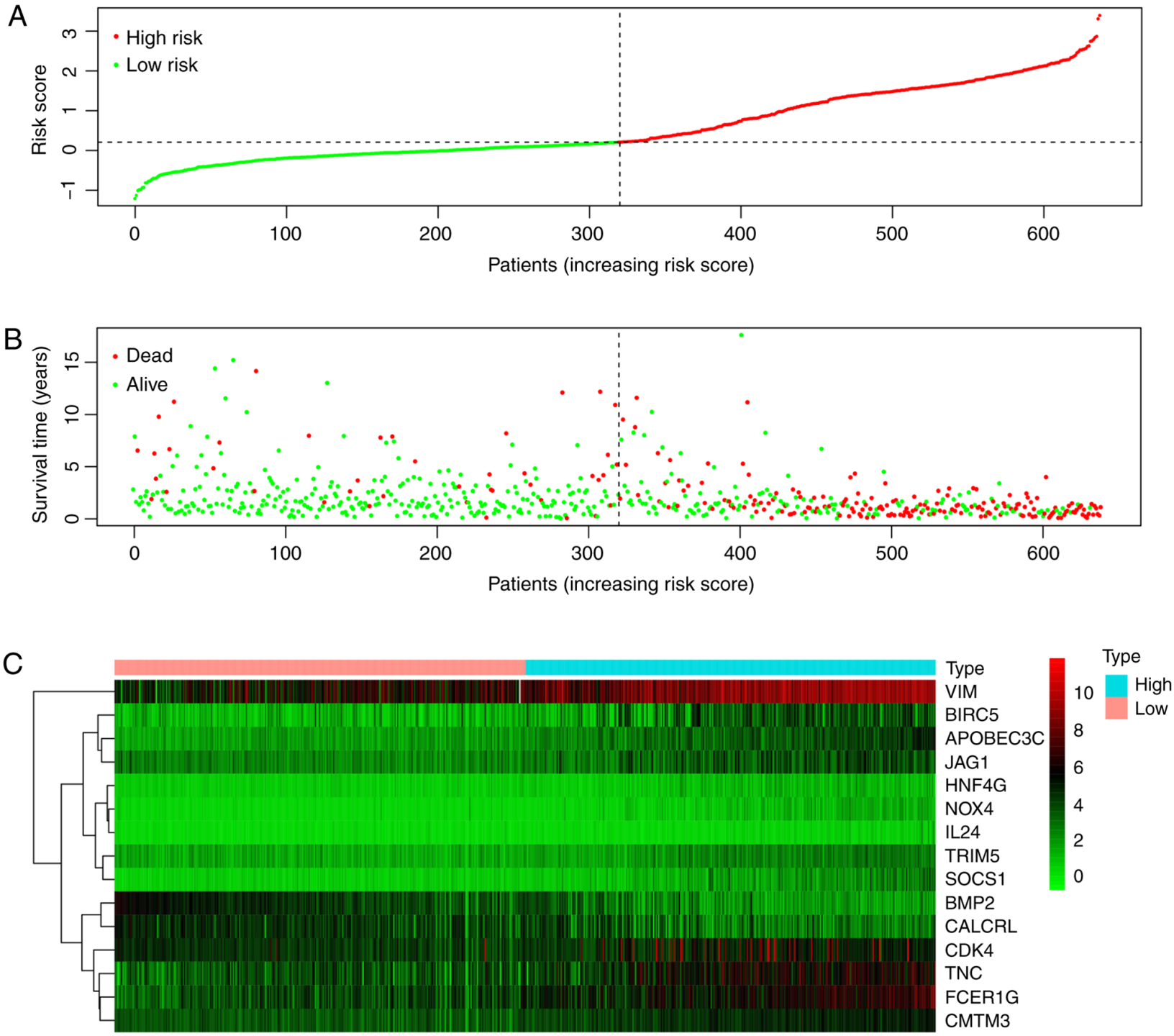

Figure 4. Construction of the IRGs prognostic model. (A) Rank and group distribution of the prognostic index. (B) Survival status of patients in different risk groups. (C) Heatmap of expression profiles of included IRGs. IRGs, immune-related genes.

six different types of immune cell infiltration (B cells, $\mathrm{CD}^{+} \mathrm{T}$ cells, $\mathrm{CD} 8^{+} \mathrm{T}$ cells, dendritic cells, macrophages and neutrophils) was analyzed using TCGA. The results (Fig. 7) demonstrated that the prognostic risk score was positively correlated with the infiltration of B cells (correlation, 0.376; $\mathrm{P}<0.001$; Fig. 7A), $\mathrm{CD}^{+} \mathrm{T}$ cells (correlation, 0.122; $\mathrm{P}=0.002$; Fig. 7C), dendritic cells (correlation, 0.306; P<0.001; Fig. 7D), macrophages (correlation, 0.317; $\mathrm{P}<0.001 ;$ Fig. 7E) and neutrophils (correlation, 0.343; $\mathrm{P}<0.001$; Fig. 7F).

Analysis and verification of gene expression. To further evaluate the expression levels of key genes in the prognosis model, five genes (CDK4, IL24, NOX4, BMP2 and BIRC5) were randomly selected for analysis of the expression levels in glioma tissues and adjacent healthy tissues. The expression levels of these five genes in glioma tissues and normal tissues were significantly different: CDK4 ( $<<0.001$; Fig. 8A), IL24 ( $\mathrm{P}<0.001$; Fig. 8B), NOX4 ( $\mathrm{P}<0.001$; Fig. 8C), BMP2 ( $\mathrm{P}<0.001$; Fig. 8D) and BIRC5 (P<0.026; Fig. 8E). The expression levels of these genes were higher in glioma tissues compared with normal tissues, which was consistent with TCGA and the GSE43378 dataset (Fig. 8).

\section{Discussion}

Glioma accounts for $\sim 80 \%$ of primary brain tumors in adults, and GBM is the most common type of glioma (1). The biological characteristics of glioma are diverse, and the prognosis of glioma with different pathological types varies (20). Immunotherapy has become a hot topic and research of immunotherapy for glioma is increasing rapidly, but remains unsuccessful (12). In the present study, IRGs were used to predict the prognosis of patients with glioma, which may facilitate the understanding of its clinical significance and molecular characteristics. The present study identified DEIRGs by comparing TCGA data with all immune genes. Using further survival and clinical analyses, the prognostic model and the validation model of IRGs were constructed. The prognostic model included 15 key genes (FCER1G, NOX4, TRIM5, SOCS1, APOBEC3C, BIRC5, VIM, TNC, BMP2, 

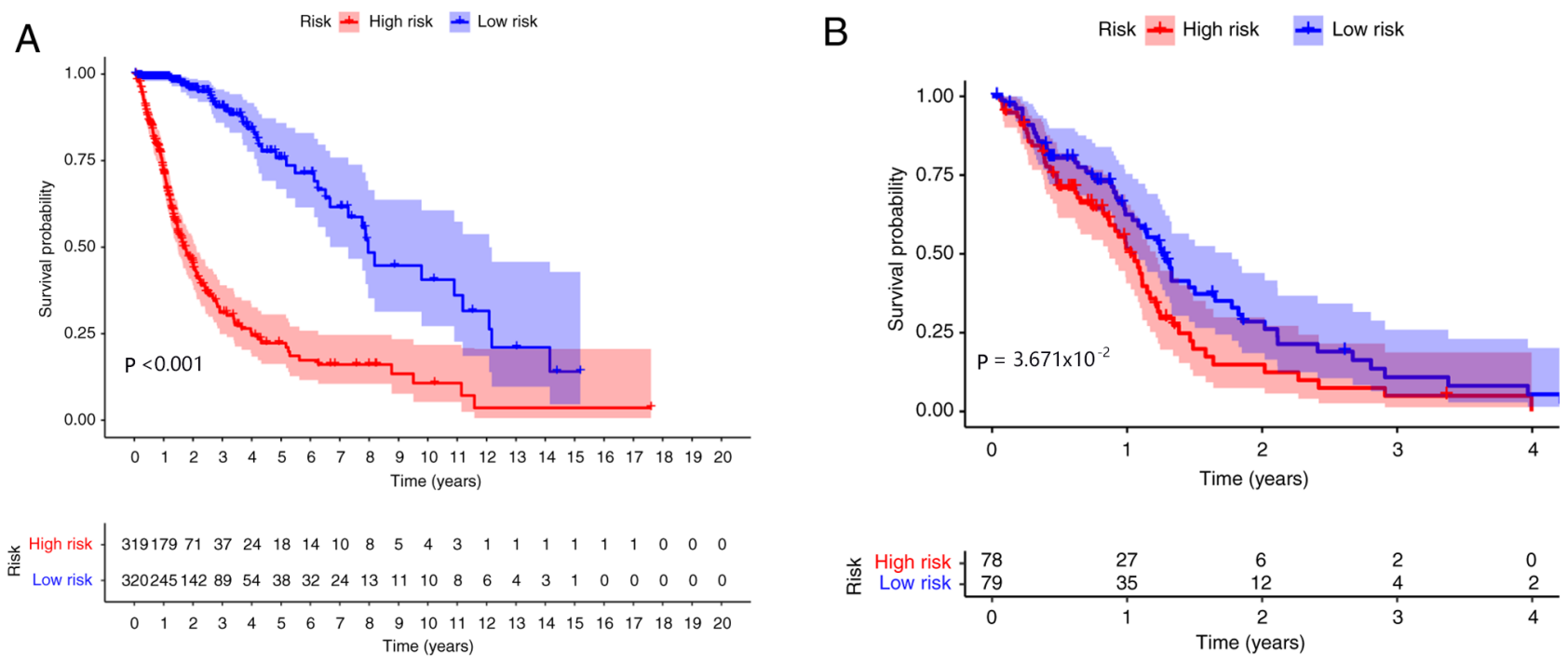

$\begin{array}{lll}\text { C } & \text { P-value } & \text { Hazard ratio(95\%Cl) } \\ \text { Age } & <0.001 & 1.073(1.061-1.084) \\ \text { Sex } & 0.414 & 1.119(0.854-1.468) \\ \text { Grade } & <0.001 & 4.702(3.779-5.850) \\ & & \\ \text { IDH1 } & 0.034 & 1.482(1.030-2.130) \\ & & \\ \text { riskscore } & <0.001 & 3.979(3.380-4.685)\end{array}$
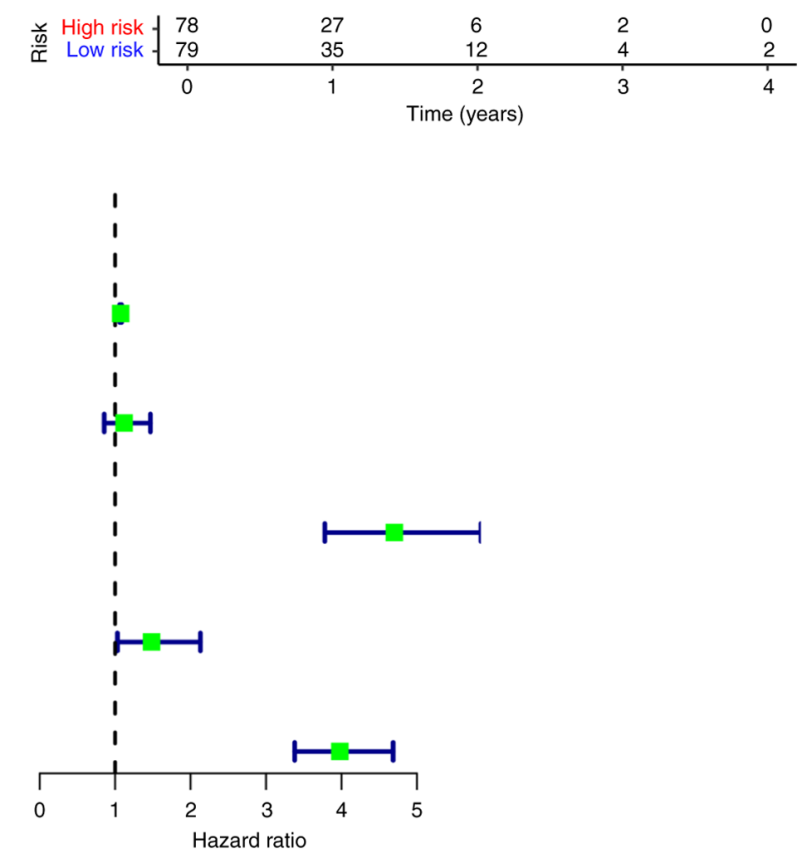

\begin{tabular}{|c|c|c|}
\hline D & $\mathrm{P}$-value & Hazard ratio $(95 \% \mathrm{Cl})$ \\
\hline Age & $<0.001$ & $1.046(1.033-1.059)$ \\
\hline Sex & 0.872 & $1.023(0.778-1.345)$ \\
\hline Grade & $<0.001$ & $1.705(1.257-2.314)$ \\
\hline IDH1 & $<0.001$ & $2.946(2.000-4.339)$ \\
\hline sksco & $<0.001$ & $2.461(1.945-3.113)$ \\
\hline
\end{tabular}

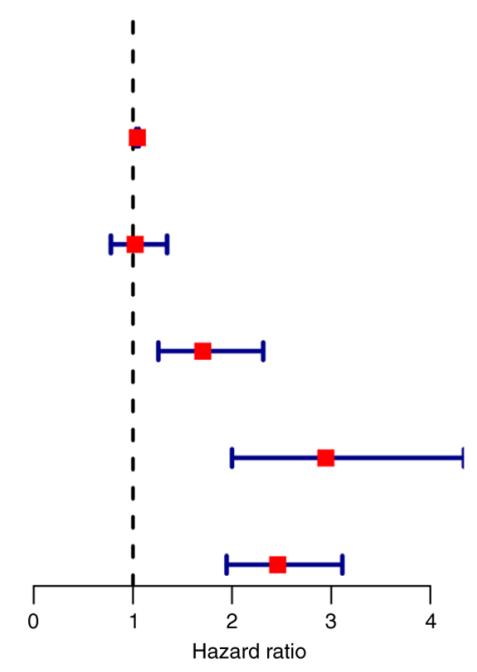

Figure 5. Survival analysis of The Cancer Genome Atlas prognostic model in glioma and glioblastoma. (A) Kaplan-Meier curve indicated that patients with glioma in the high-risk group had a lower survival probability. (B) Patients with glioblastoma in the high-risk group also had a lower survival probability. (C) Univariate Cox regression analysis of glioma. (D) Multivariate Cox regression analysis of glioma. IDH1, isocitrate dehydrogenase 1.

CMTM3, IL24, JAG1, CALCRL, HNF4G and CDK4), all of which are protein-coding genes. According to TCGA data, patients with glioma in the high-risk group had worse prognosis compared with those in the low-risk group. In addition, patients with GBM in the high-risk group had a worse outcome compared with those in the low-risk group. The prognostic model was validated using the GSE43378 dataset, and the results were consistent with the aforementioned findings. 


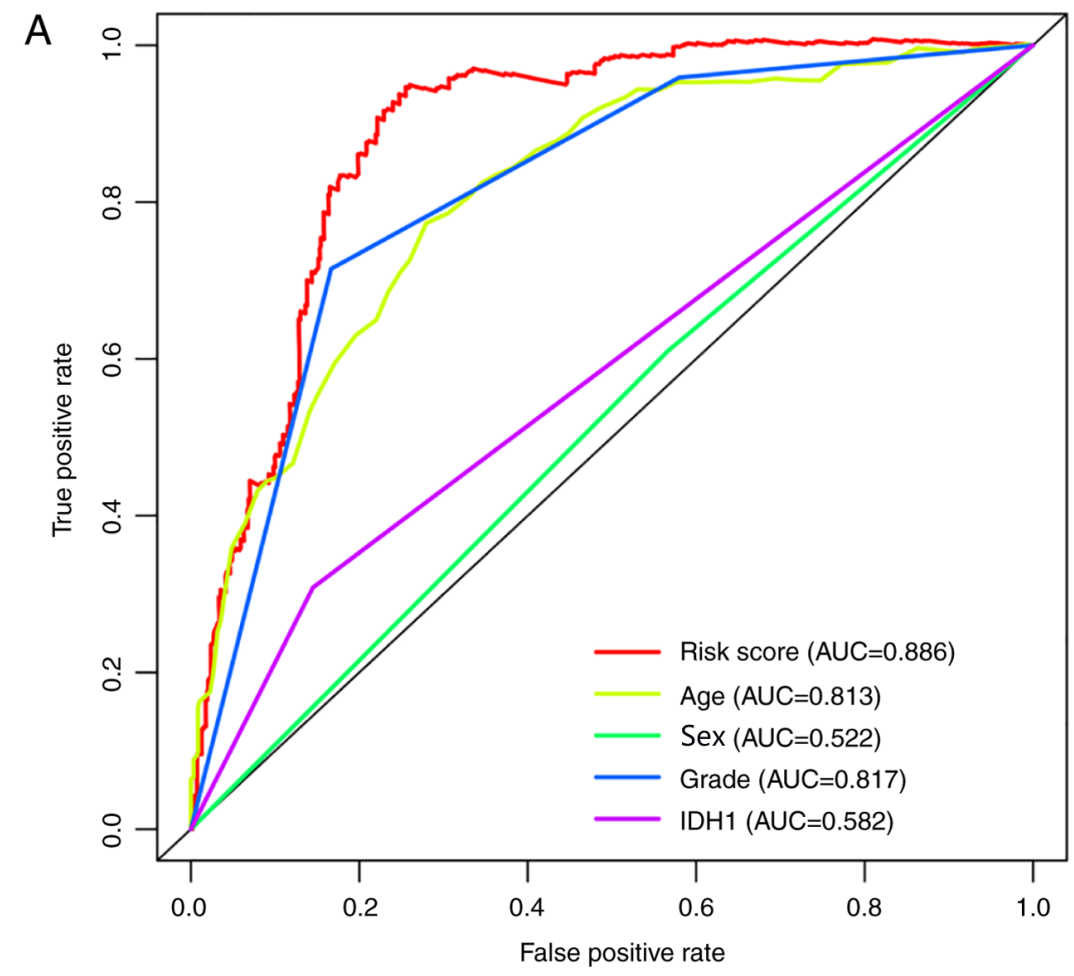

B

Points

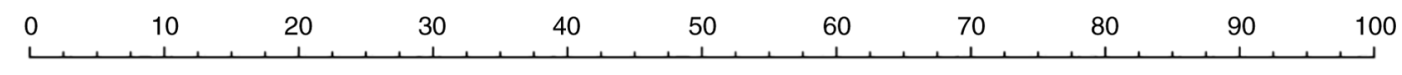

Age

\begin{tabular}{|c|c|c|c|c|c|c|}
\hline 20 & 30 & & 50 & 60 & 70 & 80 \\
\hline
\end{tabular}

Grade

G3

G2 G4

IDHWT

WT

Mutation

riskscore

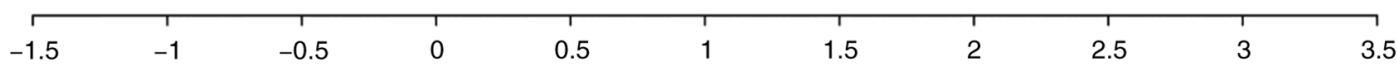

Total points

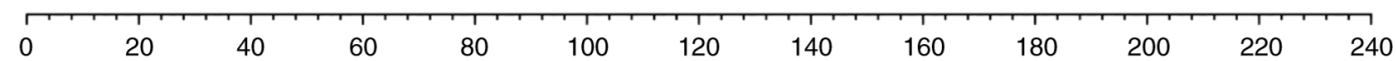

1-year survival

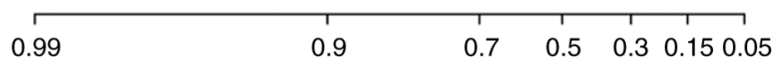

3-years survival

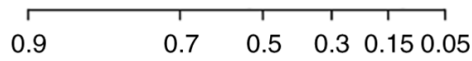

5-years survival

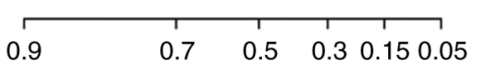

Figure 6. ROC curve and nomogram of TCGA prognostic model in glioma. (A) ROC curve of TCGA prognostic model. (B) Nomogram of TCGA model. AUC, area under the curve; IDH, isocitrate dehydrogenase; ROC, receiver operating characteristic; TCGA, The Cancer Genome Atlas; WT, wild type.

Among the 15 genes, CDK4, IL24, NOX4, BMP2 and BIRC5 were randomly selected for PCR verification.

The protein encoded by CDK4 is a member of the Ser/Thr protein kinase family, which is important for cell cycle $\mathrm{G}_{1}$ phase progression (21). A CDK4 mutation has been revealed to be associated with tumorigenesis in a variety of cancer types (22). Furthermore, CDK4/6 inhibitors not only are cytostatic, but also have immunomodulatory functions in 
A

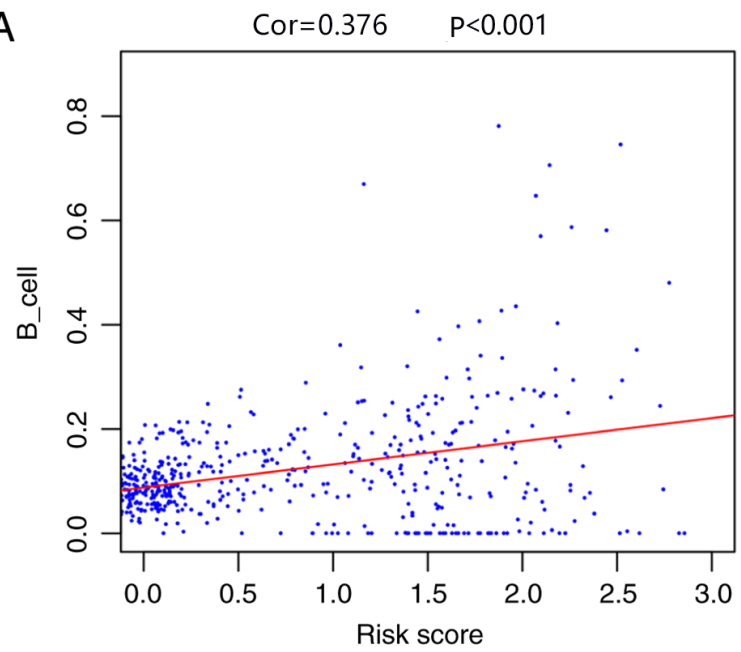

C

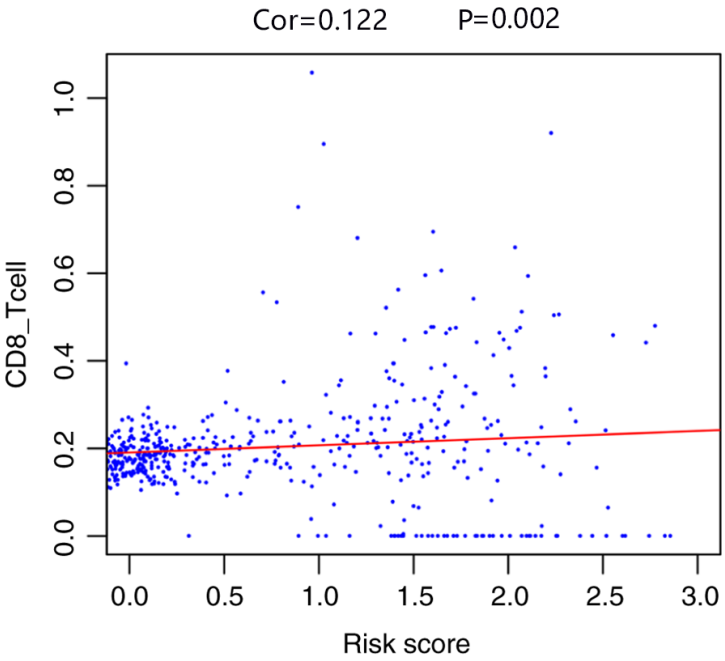

E

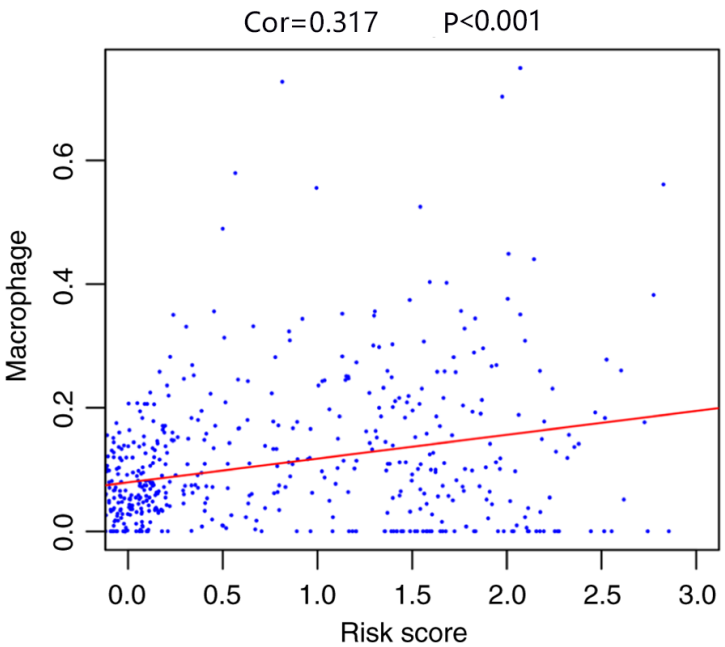

B

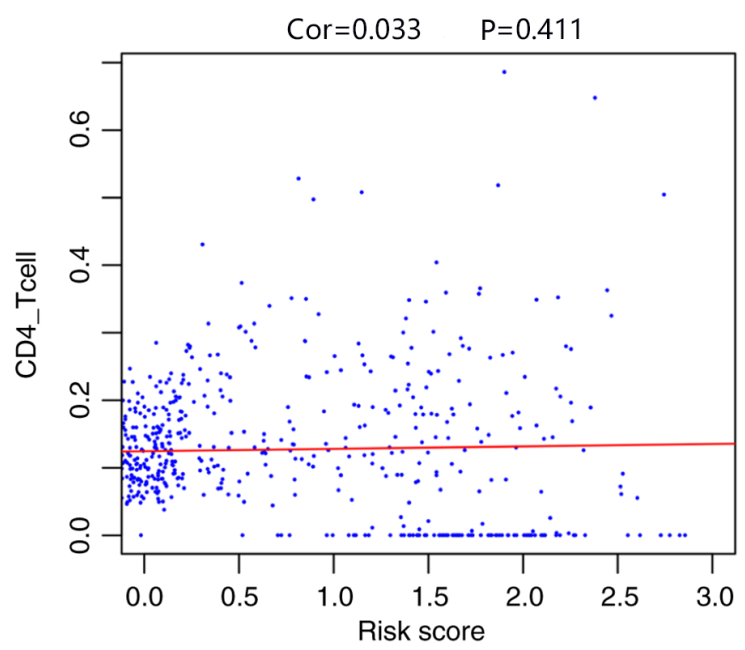

D

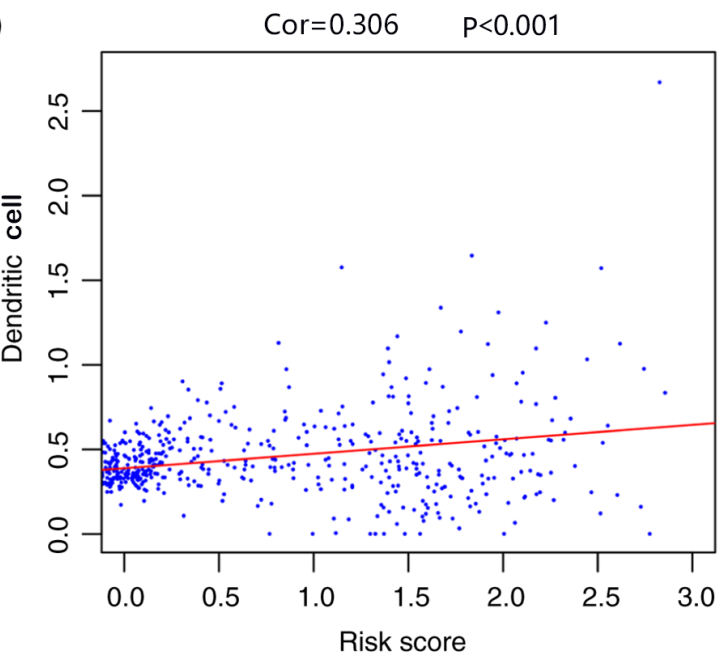

$\mathrm{F}$

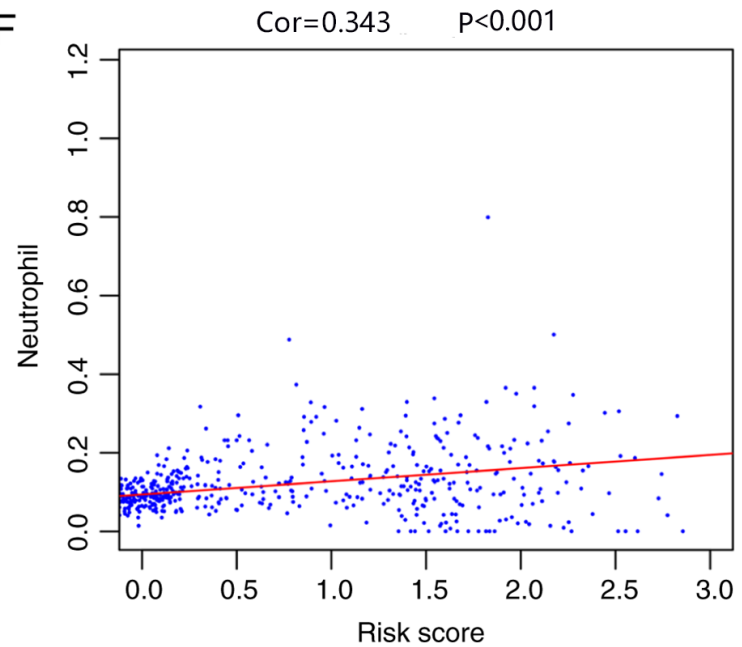

Figure 7. Associations between the risk score and infiltration abundances of six types of immune cells. (A) B cells. (B) CD4 ${ }^{+} \mathrm{T}$ cells. (C) CD8 $8^{+} \mathrm{T}$ cells. (D) Dendritic cells. (E) Macrophages. (F) Neutrophils. Cor, correlation.

tumors (23). It has been reported that CDK4 is highly expressed in GBM, and is involved in the process of glioma induced by the circular RNA(circ) MMP9/microRNA (miR)-124 axis (24).

The NADPH oxidase family has been demonstrated to be the main source of reactive oxygen species production in various cells (25). NOX4 is abundantly expressed in GBM, and may serve a vital role in the invasion, angiogenesis and radioresistance of GBM (26). The BIRC5 gene is a member of the inhibitor of apoptosis gene family, which is highly expressed during fetal development and in most tumors (27). A recent study reported that patients with non-small cell lung cancer with high anti-BIRC5 IgG expression had an improved 

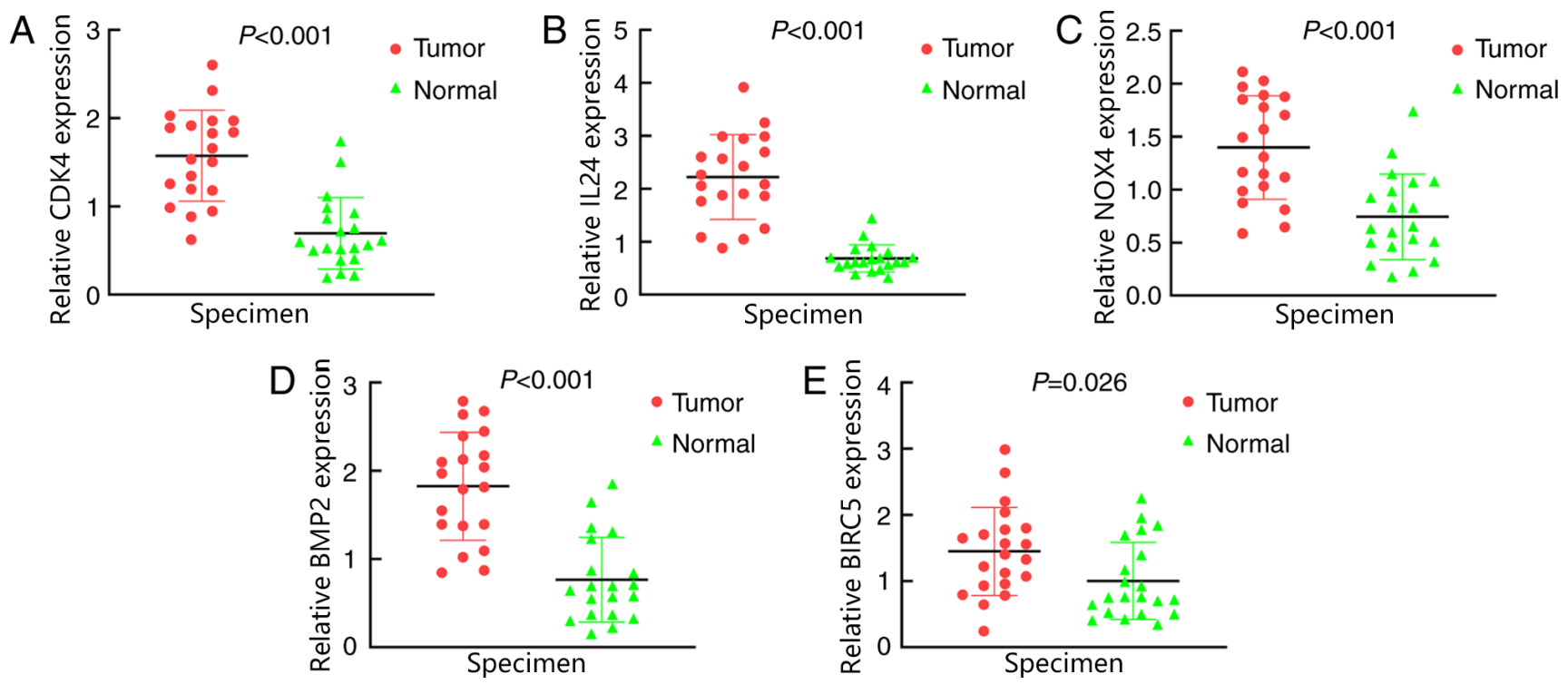

Figure 8. Expression levels of CDK4, IL24, NOX4, BMP2 and BIRC5 in tumor tissues and adjacent tissues of patients with glioma. Expression levels of (A) CDK4, (B) IL24, (C) NOX4, (D) BMP2 and (E) BIRC5. BIRC5, baculoviral IAP repeat containing 5; BMP2, bone morphogenetic protein 2; NOX4, NADPH oxidase 4.

prognosis (28). Additionally, in glioma tissues, the mRNA levels of Yes1 associated transcriptional regulator/tafazzin and its target gene BIRC5 are markedly upregulated (29).

IL24 expression can promote apoptosis and has been regarded as a tumor suppressor (30). IL24 can also induce the secretion of proinflammatory cytokines and the induction of Th1 type cytokines in monocytes, suggesting that IL24 serves an important role in tumor immunity (31). In the present study, IL24 expression was upregulated in glioma and was associated with high-risk score. Furthermore, RT-qPCR results demonstrated that IL24 expression in glioma was upregulated compared with that in healthy tissue.

BMP2 can promote differentiation and growth inhibition in glioma $(31,32)$. Furthermore, BMP2 expression is associated with WHO grade, which may be expected to be an independent prognostic factor (33). In the present study, BMP2 was highly expressed in glioma, but it was negatively associated with the risk score.

Tumor immunotherapy has gained increased attention; however, tumor-related immunosuppression remains a challenge. Therefore, it is necessary to understand the tumor-related immune signaling pathway. To improve the understanding of the underlying biological mechanism of the IRGs, the present study identified five key KEGG pathways ('Neuroactive ligand-receptor interaction', 'Cytokine-cytokine receptor interaction', 'Viral protein interaction with cytokine and cytokine receptor', 'Intestinal immune network for IgA production' and 'cAMP signaling pathway').

The 'Neuroactive ligand-receptor interaction' signaling pathway mainly involved downregulated genes in the visual network. Furthermore, the 'Neuroactive ligand-receptor interaction' and 'Cytokine-cytokine receptor interaction' signaling pathways have been reported in neurodegenerative diseases (34) and GBM $(35,36)$. In a study of prognostic markers of GBM, Zhou et al (37) identified that upregulated DEGs were enriched in cytokine-cytokine receptor interaction and circadian entrainment, while the downregulated DEG was enriched in neuroactive ligand-receptor interaction and transforming growth factor- $\beta$ signaling pathways, which was consistent with the current results. A comprehensive analysis suggested that patients with GBM with defective 'neuroactive ligand-receptor interaction' signaling pathway have a poor prognosis (38), while another study has demonstrated that 'Cytokine-cytokine receptor interaction' is one of the main long non-coding RNA enrichment signaling pathways in low-grade glioma (39).

The 'Intestinal immune network for IgA production' signaling pathway is associated with inflammatory immune diseases, including kidney diseases and osteoarthritis $(40,41)$, and is emerging as a novel target of potential therapeutic interventions (42). As an important metabolic pathway, the activation of the 'cAMP signaling pathway' has also been reported to inhibit proliferation of glioma $(43,44)$. For instance, oncogenic cAMP/Protein Kinase A Inhibitor signal transduction is implicated in the occurrence and development of various human cancer types (45). It has been demonstrated that miR-150 can inhibit the activity of PI3K and AKT via the cAMP-PKA-C-terminal Src kinase signaling pathway (46). In addition, it has been reported that the association between the cAMP signaling pathway and the MAPK signaling pathway may provide a potential strategy for glioma treatment (47). Furthermore, Daniel et al (48) revealed that in GBM, sensitive cells can be efficiently killed by cAMP agonists, and targeting both the cAMP and MAPK signaling pathways leads to the apoptosis of resistant GBM cells.

Glioma cells can secrete a variety of immunoregulatory factors, attracting several types of cells, including immune cells, into the tumor microenvironment (TME) (49). A previous study has demonstrated that the different content of glioma immune cells is associated with varying prognosis (50). Glioma-related macrophages and microglia, together with dendritic cells and neutrophils, constitute the glioma TME, regulating and inhibiting the tumor immune response (12). In the present study, multivariate Cox regression analysis identified that age, grade, 
IDH1 and risk score were independent prognostic factors. Furthermore, IDH1-WT was associated with poor prognosis and was an independent prognostic factor for OS. Glioma with IDH mutation has a $\mathrm{CpG}$ island methylation phenotype, and the survival time of patients with this is longer compared with that of patients with IDH-WT (5). Therefore, the difference in the immune-related cell content may be a potential important factor in the varying survival rates between the two tumor types. Furthermore, the present results suggested that the infiltration of B cells, $\mathrm{CD}^{+} \mathrm{T}$ cells, dendritic cells, macrophages and neutrophils was correlated with the prognostic risk score. Therefore, it was speculated that the increased infiltration of these cells was associated with poor prognosis.

Macrophages are the main cell type of the immune system and key drivers of inflammation (51). During tumor progression, macrophages establish an inflammatory environment, which stimulates angiogenesis, enhances the migration and invasion of tumor cells and inhibits antitumor immunity (52). Previous studies have reported that the accumulation of tumor-associated macrophages is associated with poor clinical prognosis $(53,54)$. Dendritic cells are antigen-presenting cells, which are necessary for T-cell-mediated immunity, and serve a crucial role in the initial activation of tumor immunity (55). Additionally, dendritic cell maturation is required to provide co-stimulatory signals to $\mathrm{T}$ cells; however, this is often not sufficient to induce effective immunity in tumors (56). Furthermore, tumor cells can use dendritic cells to escape immunity in the cancer environment (57). B cells are an important cell component of immunity in humans, and serve a role in biological functions, such as antigen presentation, activation of $\mathrm{T}$ cells and secretion of antibodies (58). In addition, it has been suggested that B cells and the differentiation-related molecular signaling pathways are involved in tumor promotion (59). Furthermore, neutrophils are key effector cells in the immune system. However, compared with other immune cells, the role of neutrophils in the pathogenesis of tumors remains unknown. Neutrophils are generally considered to have a defensive response to tumor cells, but there is increasing evidence that tumor-related neutrophils are associated with tumor progression $(60,61)$. Furthermore, clinical analysis has demonstrated that neutrophil count can be used as a biomarker to predict the prognosis of several types of tumors $(62,63)$.

In conclusion, the present study established a prognosis model based on IRGs to predict the immune status and clinical prognosis of patients with glioma. Multivariate Cox analysis demonstrated that the risk score could be used as an independent predictor of glioma. The association between the risk score and immune cell infiltration provided a basis for the prognosis and immunotherapy of glioma. However, there are some limitations to the present study. Firstly, the prognosis model involved 15 prognosis-related IRGs, which is not concise and effective enough. Therefore, future research will aim to construct a more concise and stable prognostic model. In addition, the function of some genes in this model remains unknown. Therefore, studies should further investigate the function and mechanism of these genes in immunity.

\section{Acknowledgements}

Not applicable.

\section{Funding}

The present study was funded by the Science and Education for Health Foundation of Suzhou for Youth (grant nos. kjxw2018030 and kjxw2018032), Science and Technology Project Foundation of Suzhou (grant no. SS201651), and Education Research Project Foundation of Nanjing Medical University (grant no. FZS-ZD-201701).

\section{Availability of data and materials}

The datasets generated and/or analyzed during the current study are available in the TCGA (https://portal.gdc.cancer. gov/) and GEO (https://www.ncbi.nlm.nih.gov/geo/) repository. The datasets used and/or analyzed during the current study are available from the corresponding author on reasonable request.

\section{Authors' contributions}

ZLD amd BLZ contributed to conception and design of the study. XYC, WJW, HW and JZ contributed to the data acquisition, data analysis and interpretation of the study. JJW, XW, YHQ and LX performed the statistical analysis. JJW wrote the first draft of the manuscript. JMW and XYC were involved in organizing the database, drafting the manuscript and revising it critically for important intellectual content. ZLD, HW and JMW gave final approval of the version to be published. All authors contributed to manuscript revision. All authors read and approved the final manuscript.

\section{Ethics approval and consent to participate}

The research was performed according to the principles set out in the Declaration of Helsinki 1964 and all subsequent revisions. The present study was approved by the Medical Ethics Committees of the Affiliated Suzhou Hospital of Nanjing Medical University. Written informed consent was collected from the patients/legal guardians.

\section{Patient consent for publication}

Not applicable.

\section{Competing interests}

The authors declare that they have no competing interests.

\section{References}

1. Chowdhury FA, Hossain MK, Mostofa AGM, Akbor MM and Bin Sayeed MS: Therapeutic potential of thymoquinone in glioblastoma treatment: Targeting major gliomagenesis signaling pathways. Biomed Res Int 2018: 4010629, 2018.

2. Ostrom QT, Gittleman H, Truitt G, Boscia A, Kruchko C and Barnholtz-Sloan JS: CBTRUS statistical report: Primary brain and other central nervous system tumors diagnosed in the United States in 2011-2015. Neuro Oncol 20 (Suppl 4): iv1-iv86, 2018.

3. Dewitt JC, Mock A and Louis DN: The 2016 WHO classification of central nervous system tumors: What neurologists need to know. Curr Opin Neurol 30: 643-649, 2017.

4. Walker AE, Robins M and Weinfeld FD: Epidemiology of brain tumors The national survey of intracranial neoplasms. Neurology 35: 219-226, 1985. 
5. Amankulor NM, Kim Y, Arora S, Kargl J, Szulzewsky F, Hanke M, Margineantu DH, Rao A, Bolouri H, Delrow J, et al: Mutant IDH1 regulates the tumor-associated immune system in gliomas. Genes Dev 31: 774-786, 2017.

6. Venur VA, Peereboom DM and Ahluwalia MS: Current medical treatment of glioblastoma. Cancer Treat Res 163: 103-115, 2015.

7. Kang JH, Adamson C: Novel chemotherapeutics and other therapies for treating high-grade glioma. Expert Opin Investig Drugs 24: 1361-1379, 2015.

8. Shannon K, Koehne W, Heyman MB and Koerper MA: Relapsing post-hepatitis aplastic anemia. Immunosuppressive therapy. Clin Pediatr (Phila) 29: 25-29, 1990.

9. Giraldo NA, Becht E, Remark R, Damotte D, Sautès-Fridman C and Fridman WH: The immune contexture of primary and metastatic human tumour. Curr Opin Immunol 27: 8-15, 2014.

10. Kim R, Emi M and Tanabe K: Cancer immunoediting from immune surveillance to immune escape. Immunology 121: 1-14, 2007.

11. Finocchiaro $\mathrm{G}$ and Pellegatta S: Immunotherapy for glioma: Getting closer to the clinical arena? Curr Opin Neurol 24 641-647, 2011.

12. Borisov KE and Sakaeva DD: The immunosuppressive microenvironment of malignant gliomas. Arkh Patol 77: 54-63, 2015 (In Russian).

13. Liu J, Lichtenberg T, Hoadley KA, Poisson LM, Lazar AJ, Cherniack AD, Kovatich AJ, Benz CC, Levine DA, Lee AV, et al: Abstract 3287: An integrated TCGA pan-cancer clinical data resource to drive high quality survival outcome analytics. Cancer Res 78 (Suppl 13): S3287, 2018.

14. Kawaguchi A, Yajima N, Tsuchiya N, Homma J, Sano M, Natsumeda M, Takahashi H, Fujii Y, Kakuma T and Yamanaka R: Gene expression signature-based prognostic risk score in patients with glioblastoma. Cancer Sci 104: 1205-1210, 2013.

15. Bhattacharya S, Andorf S, Gomes L, Dunn P, Schaefer H, Pontius J, Berger P, Desborough V, Smith T, Campbell J, et al: ImmPort: Disseminating data to the public for the future of immunology. Immunol Res 58: 234-239, 2014

16. Macklaim JM, Fernandes AD, Di Bella JM, Hammond JA, Reid G and Gloor GB: Comparative meta-RNA-seq of the vaginal microbiota and differential expression by Lactobacillus iners in health and dysbiosis. Microbiome 1: 12, 2013.

17. Lee S, Han S, Ju HS, Kim SY, Won HJ, Shin YM, Kim PN, An J, Lee D, Kim KM, et al: A patient-based nomogram for predicting overall survival after radiofrequency ablation for hepatocellular carcinoma. J Vasc Interv Radiol 26: 1787-1794.e1, 2015

18. Zeelen C, Paus C, Draper D, Heskamp S, Signore A, Galli F, Griessinger CM and Aarntzen EH: In-vivo imaging of tumor-infiltrating immune cells: Implications for cancer immunotherapy. Q J Nucl Med Mol Imaging 62: 56-77, 2018.

19. Livak KJ and Schmittgen TD: Analysis of relative gene expression data using real-time quantitative PCR and the 2(-Delta Delta C(T)) method. Methods 25: 402-408, 2001.

20. Ivliev AE, 't Hoen PA and Sergeeva MG: Coexpression network analysis identifies transcriptional modules related to proastrocytic differentiation and sprouty signaling in glioma. Cancer Res 70: 10060-10070, 2010.

21. Zhang J, Bu X, Wang H, Zhu Y, Geng Y, Nihira NT, Tan Y, Ci Y, Wu F, Dai X, et al: Cyclin D-CDK4 kinase destabilizes PD-L1 via cullin 3-SPOP to control cancer immune surveillance. Nature 553: 91-95, 2018.

22. Scimè A, Li L, Ciavarra G and Whyte P: Cyclin D1/cdk4 can interact with E2F4/DP1 and disrupts its DNA-binding capacity. J Cell Physiol 214: 568-581, 2008.

23. Dean JL, Mcclendon AK, Hickey TE, Butler LM, Tilley WD, Witkiewicz AK and Knudsen ES: Therapeutic response to CDK4/6 inhibition in breast cancer defined by ex vivo analyses of human tumors. Cell Cycle 11: 2756-2761, 2012

24. Silber J, Lim DA, Petritsch C, Persson AI, Maunakea AK, Yu M, Vandenberg SR, Ginzinger DG, James CD, Costello JF, et al: miR-124 and miR-137 inhibit proliferation of glioblastoma multiforme cells and induce differentiation of brain tumor stem cells. BMC Med 6: 14, 2008

25. Szöcs K, Lassègue B, Sorescu D, Hilenski LL, Valppu L, Couse TL, Wilcox JN, Quinn MT, Lambeth JD and Griendling KK: Upregulation of Nox-based NAD(P)H oxidases in restenosis after carotid injury. Arterioscler Thromb Vasc Biol 22: 21-27, 2002

26. Li Y, Han N, Yin T, Huang L, Liu S, Liu D, Xie C and Zhang M: Lentivirus-mediated Nox4 shRNA invasion and angiogenesis and enhances radiosensitivity in human glioblastoma. Oxid Med Cell Longev 2014: 581732, 2014.
27. Gressot LV, Doucette T, Yang Y, Fuller GN, Manyam G, Rao A, Latha K and Rao G: Analysis of the inhibitors of apoptosis identifies BIRC3 as a facilitator of malignant progression in glioma. Oncotarget 8: 12695-12704, 2017.

28. Zhao H, Zhang X, Han Z, Wang Z and Wang Y: Plasma anti-BIRC5 IgG may be a useful marker for evaluating the prognosis of nonsmall cell lung cancer. Febs Open Bio 8: 829-835, 2018.

29. Zhang H, Geng D, Gao J, Qi Y, Shi Y, Wang Y, Jiang Y, Zhang Y, Fu J, Dong Y, et al: Expression and significance of Hippo/YAP signaling in glioma progression. Tumour Biol 37: 15665-15676, 2016.

30. Ma YF, Ren Y, Wu CJ, Zhao XH, Xu H, Wu DZ, Xu J, Zhang XL and Ji Y: Interleukin (IL)-24 transforms the tumor microenvironment and induces anticancer immunity in a murine model of colon cancer. Mol Immunol 75: 11-20, 2016.

31. Nagakawa H, Shimozato O, Yu L, Wada A, Kawamura K, Li Q, Chada S, Tada Y, Takiguchi Y, Tatsumi K and Tagawa M: Expression of a murine homolog of apoptosis-inducing human IL-24/MDA-7 in murine tumors fails to induce apoptosis or produce anti-tumor effects. Cell Immunol 275: 90-97, 2012.

32. Zhou A, Lin K, Zhang S, Chen Y, Zhang N, Xue J, Wang Z, Aldape KD, Xie K, Woodgett JR and Huang S: Nuclear GSK $3 \beta$ promotes tumorigenesis by phosphorylating KDM1A and inducing its deubiquitylation by USP22. Nat Cell Biol 18: 954-966, 2016

33. Yang X, Li D, Cheng S, Fan K, Sheng L, Zhang J, Feng B and $\mathrm{Xu} \mathrm{Z}$ : The correlation of bone morphogenetic protein 2 with poor prognosis in glioma patients. Tumour Biol 35: 11091-11095, 2014.

34. Hollinger DM and Rossiter RJ: Chemical studies of peripheral nerve during wallerian degeneration. V. B-Glucuronidase. Biochem J 52: 659-663, 1952

35. Tong L, Yi L, Liu P, Abeysekera IR, Hai L, Li T, Tao Z, Ma H, Xie Y, Huang Y, et al: Tumour cell dormancy as a contributor to the reduced survival of GBM patients who received standard therapy. Oncol Rep 40: 463-471, 2018.

36. Nijaguna MB, Patil V, Hegde AS, Chandramouli BA, Arivazhagan A, Santosh V and Somasundaram K: An eighteen serum cytokine signature for discriminating glioma from normal healthy individuals. PLoS One 10: e0137524, 2015.

37. Zhou L, Tang H, Wang F, Chen L, Ou S, Wu T, Xu J and Guo K: Bioinformatics analyses of significant genes, related pathways and candidate prognostic biomarkers in glioblastoma. Mol Med Rep 18: 4185-4196, 2018.

38. Pal J, Patil V, Kumar A, Kaur K, Sarkar C and Somasundaram K: Loss-of-function mutations in Calcitonin receptor (CALCR) identify highly aggressive glioblastoma with poor outcome. Clin Cancer Res 24: 1448-1458, 2018.

39. Reon BJ, Anaya J, Zhang Y, Mandell J, Purow B, Abounader R and Dutta A: Expression of lncRNAs in low-grade gliomas and glioblastoma multiforme: An in silico analysis. PLoS Med 13: e1002192, 2016.

40. Li M and Yu XQ: Genetic determinants of $\operatorname{IgA}$ nephropathy: Eastern perspective. Semin Nephrol 38: 455-460, 2018.

41. Feagan BG, Schreiber S, Wolf DC, Axler JL, Kaviya A, James A, Curtis RI, Geransar P, Stallmach A, Ehehalt R, et al: Sustained clinical remission with vedolizumab in patients with moderate-to-severe ulcerative colitis. Inflamm Bowel Dis 25: 1028-1035, 2019.

42. Magistroni R, D'Agati VD, Appel GB and Kiryluk K: New developments in the genetics, pathogenesis, and therapy of $\operatorname{IgA}$ nephropathy. Kidney Int 88: 974-989, 2015.

43. Chen X, Zang W, Xue F, Shen Z and Zhang Q: Bioinformatics analysis reveals potential candidate drugs for different subtypes of glioma. Neurol Sci 34: 1139-1143, 2013.

44. Fu H, Ge B, Chen D, Wu Y, Luo Q, Li X, Zheng C and Tang Q: Phytanoyl-CoA 2-hydroxylase-interacting protein-like gene is a therapeutic target gene for glioblastoma multiforme. Med Sci Monit 25: 2583-2590, 2019

45. Hussain M, Shah Z, Abbas N, Javeed A, Mukhtar MM and Zhang J: Targeting tumor-associated immune suppression with selective protein kinase A type I (PKAI) inhibitors may enhance cancer immunotherapy. Med Hypotheses 86: 56-59, 2016.

46. Sang W, Wang Y, Zhang C, Zhang D, Sun C, Niu M, Zhang Z, Wei X, Pan B, Chen W, et al: MiR-150 impairs inflammatory cytokine production by targeting ARRB-2 after blocking CD28/B7 costimulatory pathway. Immunol Lett 172: 1-10, 2016. 
47. Lv P, Wang W, Cao Z, Zhao D, Zhao G, Li D, Qi L and Xu J: Fsk and IBMX inhibit proliferation and proapoptotic of glioma stem cells via activation of cAMP signaling pathway. J Cell Biochem 120: 321-331, 2019.

48. Daniel PM, Filiz G and Mantamadiotis T: Sensitivity of GBM cells to cAMP agonist-mediated apoptosis correlates with CD44 expression and agonist resistance with MAPK signaling. Cell Death Dis 7: e2494, 2016.

49. Han SJ, Zygourakis C, Lim M and Parsa AT: Immunotherapy for glioma: Promises and challenges. Neurosurg Clin N Am 23: 357-370, 2012.

50. Bullard DE, Gillespie GY, Mahaley MS and Bigner DD: Immunobiology of human glioma. Semin Oncol 13: 94-109, 1986.

51. Winfield JB. Role of phagocytosis in macrophage function in an in vitro primary immune system. Cell Immunol 2: 690-695, 1971.

52. Mantovani A, Marchesi F, Malesci A, Laghi L and Allavena P: Tumour-associated macrophages as treatment targets in oncology. Nat Rev Clin Oncol 14: 399-416, 2017.

53. Choi J, Gyamfi J, Jang H and Koo JS: The role of tumor-associated macrophage in breast cancer biology. Histol Histopathol 33: 133-145, 2018

54. Yin J, Valin KL, Dixon ML and Leavenworth JW: The role of microglia and macrophages in CNS homeostasis, autoimmunity, and cancer. J Immunol Res 2017: 5150678, 2017.

55. Abediankenari S, Janbabaei Mollae G, Ghasemi M, Yousefzadeh Y, Bahrami $\mathrm{M}$ and Alimoghaddam $\mathrm{K}$ : Vaccination of diffuse large B-cell lymphoma patients with antigen-primed dendritic cells. Acta Med Iran 51: 284-288, 2013.
56. Gardner A and Ruffell B: Dendritic cells and cancer immunity. Trends Immunol 37: 855-865, 2016.

57. Steinman RM and Banchereau J. Taking dendritic cells into medicine. Nature 449: 419-426, 2007.

58. Wang JZ, Zhang YH, Guo XH, Zhang HY and Zhang Y: The double-edge role of B cells in mediating antitumor T-cell immunity: Pharmacological strategies for cancer immunotherapy. Int Immunopharmacol 36: 73-85, 2016.

59. Seifert M and Küppers R: Human memory B cells. Leukemia 30: 2283-2292, 2016.

60. Ahrén B, Taborsky GJ Jr and Porte D Jr: Neuropeptidergic versus cholinergic and adrenergic regulation of islet hormone secretion. Diabetologia 29: 827-836, 1986.

61. Liang W and Ferrara N: The complex role of neutrophils in tumor angiogenesis and metastasis. Cancer Immunol Res 4: 83-91, 2016.

62. Massara M, Persico P, Bonavita O, Mollica Poeta V, Locati M, Simonelli $\mathrm{M}$ and Bonecchi R: Neutrophils in gliomas. Front Immunol 8: 1349, 2017.

63. Ocana A, Nieto-Jiménez C, Pandiella A and Templeton AJ: Neutrophils in cancer: Prognostic role and therapeutic strategies. Mol Cancer 16: 137, 2017.

(i) $€$ This work is licensed under a Creative Commons Attribution-NonCommercial-NoDerivatives 4.0 International (CC BY-NC-ND 4.0) License. 